\title{
ULTRASONIC OVARIAN DRILLING AS A FIRST CHOICE IN INFERTILE WOMEN WITH POLYCYSTIC OVARY SYNDROME
}

\author{
El-Edessy M.S (M.D), Ali A.M (M.D), El-Darwish, A.G (M.D), Samie M.A (M.D), \\ $\operatorname{Nasr} A . A(M . S c)$. \\ Department of Obstetrics and Gynecology, Faculty of Medicine, \\ Al-Azhar University-Assiut, Egypt.
}

\section{ABSTRACT}

Objective : To evaluate the results of laparoscopic ovarian drilling using harmonic scalpel in infertility patients with PCOS as a first choice as regard to ovulation rate, pregnancy rate, hormonal profile and ultrasonographic changes which reflect the ovarian reserve and reproductive outcome.

Patients and Methods: 90 patients presented by infertility due to PCOS were randomly allocated into three equal groups. Group (I) were subjected to ovulation induction by clomiphene citrate ( $50 \mathrm{mg}$ twice/day) started from the $3^{\text {rd }}$ day of normal or induced cycle for 5 days for six consecutive cycles, Group (II) subjected to laparoscopic ovarian drilling using electrocautery and Group (III) was subjected to laparoscopic ovarian drilling using harmonic scalpel. all patients were assessed twice; one before the induction procedure and the $2^{\text {nd }}$ was three months after if pregnancy did not occur. Patients were assessed clinically (to determine menstrual regularity, body mass index and degree of hirsuism), sonographically (to measure ovarian volume and antral follicle count at time of ovarian quiescence) and laboratory (to measure basal serum LH, FSH, LH/FSH ratio, total testosterone and estradiol). Also, $2^{\text {nd }}$ look laparoscopy was pefformed in those patients who failed to conceive within six months of the initial laparoscopic procedure.

Results: Laparoscopic ovarian drilling using harmonic scalpel alone resolved infertility within $4-6$ months in $57 \%$ of couples with significantly higher ovulation and pregnancy rates over clomiphene citrate and electrocautery groups with significantly more regular menstrual pattern and minimal incidence of post operative adhesions.

Conclusion: Laparoscopic ovarian drilling using harmonic scalpel is a minimally invasive procedure, leads to Monofollicular development which eliminates the need for cycle monitoring and risk of multiple pregnancies or ovarian hyperstimulation that may occur with medical induction of ovulation. It has significantly higher ovulation and pregnancy rates, more regular menstrual pattern and with minimal effect on ovarian reserve with minimal incidence of post operative adhesions.

\section{INIRODUCTION}

Polycystic ovary syndrome is the most common cause of anovulatory infertility affecting between $4 \%$ and $6 \%$ of women of reproductive age. Bilateral ovarian wedge resection. proposed by Stein and Leventhal in $1935^{(1)}$, was the only treatment available for this syndrome. However, as ovulation inducing medical agents becane avaidble, the medical induction of ovulation became the dominant form of treatment (2). Clomiphene citrate (cc) was used for a long time as a first Line of treatment However, $15-20 \%$ of women remain anovulatory despite receiving incremental doses of $\mathrm{CC}$. Furthermore, there was a discrepancy between the ovulation and conception rates. Gonadotrophin therapy is usually the next step following failure with clomiphene ${ }^{(3)}$. However, Tracy et al., (2007) stated 
that because of the peculiarly high sensitivity of polycystic ovaries to gonadotrophin stimulation it was plagued by an unacceptable rate of multiple pregnancies and ovarian hyperstimulation syndrome (4). An alternative to the medical approach is surgical treatment. The most widely used surgical treatment today is laparoscopic ovarian drilling (4) Laparoscopic ovarian drilling (LOD) alone can resolve infertility within 4-6 months in 50-60\% of couples. So, a strategy with diagnostic laparoscopy and LOD as a first choice treatment of infertility in women with PCOS will shorten the time to pregnancy, reduce the need for medical ovulation induction and enable diagnosis of those women with anatomic infertility who can achieve pregnancy only by IVF treatment ${ }^{(5)}$. The rapid acceptance of laparoscopic surgery in gynecology has brought a reevaluation of the types of energy currently used for cutting and coagulation during these procedures. Electro-surgery has undergone significant improvements with respect to safety and delivery, but there is still considerable concern with regard to unintentional tissue damage. High frequency energy holds considerable promise as a cutting and coagulation modality ${ }^{(6)}$. The ultrasonically activated scalpel (UAS) and laparoscopic coagulation shears (LCS) use high-frequency ultrasound energy and can be tried as a substitute for electro surgery. The ultrasoically activated scalpel consists of a piezoelectric transducer that is housed in a hand piece and causes a blade tip to vibrate longitudinally at an ultrasonic level $(55,500$ times per second) and excursion over a distance of 50-100 $\mu \mathrm{m}$. The thermal spread of the ultrasonically activated scalpel is about $0.05 \mathrm{~mm}$, compared with $0.35 \mathrm{~mm}$ for that produced by electrocautery ${ }^{(7)}$.

\section{AIM OF THE STUDY}

This study was conducted to evaluate the role of laparoscopic ovarian drilling using Harmonic scalpel as regard to ovulation rate, pregnancy rate, hormonal profile and ultarsonographic changes and to compare the results with that of clomiphene citrate and laparoscopic ovarian drilling by electrocautery and to compare the post operative adhesion formation of harmonic scalpel and electrocautery.

\section{PATIENT \& METHODS}

Ninety patients presented by PCOS were selected from those patients attending our infertility clinic, department of Obstetrics and Gynecology, al-Azhar University hospitals in Assiut during the period from 2005 to 2007 , They were randomly allocated into three equal groups. For each group one method of ovulation induction procedure was applied namely clomiphene citrate, LOD using electrocautery and LOD using harmonic scalpel. The diagnosis of patients depended on the Rotterdam European Society of Human Reproduction / American Society for Reproductive Medicine Sponsored PCOS Consensus Workshop Group that convened in $2003^{(8)}$, and required the existence of two of the following three criteria to make the diagnosis of PCOS: oligo-ovulation / anovulation, Clinical or biochemical signs of hyperandrogenism and Polycystic ovaries by ultrasound.

All patients were assessed clinically (to determine menstrual regularity, body mass index and degree of hirsutism), sonographically (to measure ovarian volume and antral follicle count at the time of ovarian quiescence) and laboratory (to measure serum LH, FSH, LH/FSH ratio, total testosterone and estradiol). Blood samples $(10 \mathrm{ml})$ were obtained between 8 and 9 AM, under basal conditions, in the early follicular phase (day 3 to 5 of the menstrual cycle) in oligomenorrheic patients and at random in amenorrheic ones as long as pregnancy was ruled out by pregnancy test and/or ultrasonography. Blood samples were left to clot then centrifuged $\left(4000^{\circ}\right.$ r/minute) to allow serum separation. Collected sera 
were capped in bottles and labeled, then stored at $-20^{\circ} \mathrm{C}$ until assayed. The patients were assessed twice one before the induction procedure and the other three months after, if pregnancy did not occur.

\section{Induction procedure :}

Group (I) were subjected to ovulation induction by clomiphene citrate (50 $\mathrm{mg}$ twice/day) started from the 2rd day of normal or induced cycle for 5 days for six consecutive cycles.

Group (II) subjected to laparoscopic ovarian drilling using electrocautery.

Group (III) was subjected to laparoscopic ovarian drilling using harmonic scalpel.

The laparoscopic procedure was performed in the follicular phase of natural or induced cycle. Laparoscopy was performed via three ports of entry after insuffation of the peritoneal cavity by electronic high-flow pneumoperitoneal insufflator with CO2 gas (Wisap, Germany). A 10-mm laparoseope (Olympus Laparoscope OTV-SP1, Germnay) was inserted in the primary submbilical trocar with two additional 5 -mm trocars in the lower abdomen. A grasping foreeps was used to hold the ovarian ligament for manipulation of the ovary.

In group II: the drilling was performed using an insulated unipolar electrocautery needle electrode (Surgistate II, USA), on both ovaries. The uninsulated part of the needle was $8 \mathrm{~mm}$ long and its diameter was $<1 \mathrm{~mm}$. The needle was inserted into the ovarian surface as close to perpendicularly as possible. A short duration of a cutting current of 100 Watt was used to aid the entry of the needle. The whole length of the needie was inserted into the ovary and was activated for 2-3 Seconds with 4- Watt of coagulating current at each point.

In group III: harmonic scalpel (Ethicon Ultracission, Germany) was used as a substitute for electro surgery. We used the only active (vibrating) blade of laparoscopic coagulation shear (LCS) which has a tip of about $1 \mathrm{~mm}$ and a length of about $1 \mathrm{~cm}$. After activation of the balde, the ovaries were dritled using the whole length of the active balde. A total of 6 punctures per ovary were created, depending upon the size of the ovary.

Before dritling, tubal patency and mobility were confirmed by Mushing of the tubes with Methylene blue. Women with a blocked tube or tubes were excluded from this study.

After drilling of the cysts, the ovary was allowed to cool in a pole of salme to prevent excessive heat trauma. The abdominal cavity was then rinsed with $500-1000 \mathrm{cc}$ of sterile saline to remove blood and coagulated tissue and to minimize post operative adhesions.

All patients were followed up for 6 months to evaluate the changes in menstrual pattern, hormonal profle, ultrasonographic findings, ovulation rate and pregnancy rate as well as assessment of post laparoscopic adhesions in the electrocoutery and harmonic scalpel groups by $2^{\text {nd }}$ look laparoscopy if pregnancy did not occur within six months of the Enitial procedure.

The statistical analysis was performed with the use of commercial sofwware programs (SPSS for Windows, version 9.0, and Minitab Statistical Soltware for Windows, Release 13.1). The Student's t-test for independent samples was used to compare baseline differences. Chi-square or Fisher exact tests were used as appropriate for categorical variables. A p value of less than 0.05 was considered statistically significant.

\section{RESULTS}

The base line clinical hormonal and ultrasonographic characteristics of each study group are shown in Table (I). Comparison of the preoperative hormonal characteristics of PCOS patients among the three groups showed no 
significant statistical difference.

Associated Findings :

There were 2 cases of hypertension $(2.2 \%)$ in this study, one in group I and the other in group II. Insulin dependent diabetes mellitus (IDDM) was diagnosed in 3 cases $(3.3 \%$ ), one in group II and two in group III. These findings indicate the presence of inulin resistance in PCOS patients.

Complications of the Induction Procedure :

One case $(3.3 \%)$ in the clomiphene citrate group developed ovaian hyperstimulation syndrome (OHSS) which was mild and conservatively treated. In the electrocautery group, injury to the mesovarian ligament occurred during the attempt to manipulate the ovary in one case (3.3\%). In the harmonic scalpel group, one case (3.3\%) developed mild subcutaneous emphysema which resolved spontaneously few hours after the procedure.

Fllow up and Outcomes :

85 patients were follwed up for six months, five patients were lost to follow up, one from group I and two from each of groups II and III; they were excluded from the statistics of follow up.

\section{A) Post induction menstrual pattern:}

The percentage of cases with regular cycles became significantly more in both groups II and III (92.85\% for each) compared to group I (86.2\%) $(\mathrm{P}<0.05)$. On the other hand, there was no significant difference between group II and group III as regard to menstrual regularity $(\mathrm{P}<0.05)$ (Table II).

\section{B) Post induction Hormonal profile:}

There was a significant reduction in the mean levels of $\mathrm{LH}, \mathrm{LH} / \mathrm{FSH}$ ratio and Testosterone in the three groups $(\mathrm{p}<0.05)$. On the other hand, there were no significant changes of the mean levels of FSH and E2 in any of the three groups $(\mathrm{p}>0.05)$ (Table III).

\section{C) Post-induction ultrasonographic} characteristics:

There was a reduction in both ovarian volume and antral follicle count (AFC) after each method of induction; however the reduction was statistically insignificant in C.C group and harmonic scalpel group, $(P>0.05)$. On the other hand the reduction in both ovarian volume and antral follicle count in electrocautery group was statistically significant $(\mathrm{P}<0.001)$ Table IV.

\section{D) Ovulation and pregnancy rates:}

There were significant differences in ovulation and pregnancy rates between medical ovulation induction group (group I) and surgical ovulation induction group (groups II and III), (P<0.05). On the other hand there was no significant difference in ovulation or pregnancy rates between the electrocautery group and the harmonic scalpel group $(\mathrm{P}>0.05)($ Tabel V).

\section{E) Postoperative adhesion Formation:}

Second look laparoscopy was carried out for those patients who failed to conceive after six months of the initial laparoscopic induction procedure. The total number of cases who didn't get pregnanct in group II and III was 26 patients. Six cases failed to undergo second look laparoscopy due to drop out and were excluded from the statistical analysis. The number of patients who underwent 2nd look laparoscopy was twenty patients (eleven patients from group II and nine patients from group III). Also there was an opportunity to evaluate pelvic adhesions in four patients who delivered by cesarean section in our department (two patients from each group). Assessment of post LOD adhesion formation, According to American Fertility Society (AFS) classification of adnexal adhesions 1988, showed that the incidence and type of post LOD adhesion of the harmonic scalpel group was significantly less than that produced by electrocautery (Table VI). 
Table I : Pre induction clinical, hormonal and ultrasonographic characteristics of the three groups of PCOS patients $(n=90)$.

\begin{tabular}{|c|c|c|c|}
\hline Variable & $\begin{array}{l}\text { Group (I) } \\
(\mathbf{n}=\mathbf{3 0})\end{array}$ & $\begin{array}{l}\text { Group (II) } \\
(n=30)\end{array}$ & $\begin{array}{c}\text { Group (III) } \\
(\mathrm{n}=30)\end{array}$ \\
\hline Age (years) Mean $\pm \mathrm{SD}$ & $25.1 \pm 4$ & $24.95 \pm 2.4$ & $24.8 \pm 3.1$ \\
\hline Duration of infertility (years) Mean $\pm S D$ & $4.3 \pm 3$ & $5.4 \pm 2.4$ & $6.2 \pm 2.4$ \\
\hline \multicolumn{4}{|l|}{ Menstrual pattern $[$ No. $(\%)]$} \\
\hline - Oligomenorrhea & $22(73.3 \%)$ & $20(66.7 \%)$ & $21(70.0 \%)$ \\
\hline - 2ry amenorrhea & $7(23.3 \%)$ & $9(30 \%)$ & $8(26.6 \%)$ \\
\hline - Polymenorrhea & $1(3.4 \%)$ & $1(3.6 \%)$ & $1(3.4 \%)$ \\
\hline $\mathrm{BMI}\left(\mathrm{Kg} / \mathrm{m}^{2}\right)$ Mean $\pm \mathrm{SD}$ & $29.8 \pm 5.97$ & $28.7 \pm 3.86$ & $29.1 \pm 4.7$ \\
\hline \multicolumn{4}{|l|}{ Classification [No.(\%)] } \\
\hline - Normal & $6(20 \%)$ & $8(26.7 \%)$ & $5(16.7 \not)$ \\
\hline - Overweight & $12(40 \%)$ & $12(40 \%)$ & $14(46.6 \%)$ \\
\hline - Obese & $12(40 \%)$ & $10(33.7 \%)$ & $11(36.7 \%)$ \\
\hline \multicolumn{4}{|l|}{ Hirsutism [No.(\%)] } \\
\hline - Non & $6(20 \%)$ & $7(23.3 \%)$ & $6(20 \%)$ \\
\hline - Mild & $13(43.3 \%)$ & $12(40 \%)$ & $12(40 \%)$ \\
\hline - Moderate & $7(23.3 \%)$ & $6(20 \%)$ & $6(20 \%)$ \\
\hline - Severe & $4(13.4 \%)$ & $5(16.7 \%)$ & $6(20 \%)$ \\
\hline \multicolumn{4}{|l|}{ Hormonal profile (Mean \pm SD) } \\
\hline - $\mathrm{LH}(\mathrm{IU} / \mathrm{L})$ & $12.87 \pm 2.28$ & $13.1 \pm 2.11$ & $12.8 \pm 1.88$ \\
\hline - FSH (IU/L) & $5.9 \pm 1.2$ & $5.69 \pm 0.93$ & $5.3 \pm 0.93$ \\
\hline - LH: FSH ratio & $2.25 \pm 0.56$ & $2.36 \pm 0.54$ & $2.49 \pm 0.57$ \\
\hline - Total testost. (ng/ml) & $0.95 \pm 0.15$ & $0.96 \pm 0.16$ & $0.96 \pm 0.14$ \\
\hline - Serum E2 (pg/mL & $75.3 \pm 4.87$ & $75.77 \pm 6.13$ & $77.9 \pm 5.24$ \\
\hline \multicolumn{4}{|l|}{ Ultrasonographic characteristics (Mean $\pm \mathrm{SD}$ ) } \\
\hline - Ovarian volume $(\mathrm{cm} 3)$ & $11.68 \pm 2.4$ & $11.66 \pm 2.17$ & $12.5 \pm 1.66$ \\
\hline - Antral follicle count (AFC) & $16 \pm 1.9$ & $16.1 \pm 2$ & $16 \pm 2.3$ \\
\hline
\end{tabular}

There were no significant differences among the three groups $(\mathrm{P}>0.05$ ). 
Table II : Menstrual pattern before and after different methods of ovulation induction during the period of follow up .

\begin{tabular}{|c|c|c|c|}
\hline Menstrual pattern & Pre induction & Post induction & P value \\
\hline \multicolumn{4}{|l|}{ Group (I) : Clomiphene citrate } \\
\hline - Normal cycle & $0(0 \%)$ & $25(86.2 \%)$ & \multirow{5}{*}{$<0.01$} \\
\hline - Oligomenorrhea & $22(73.3 \%)$ & $4(13.8 \%)$ & \\
\hline - 2ry amenorrhea & $7(23.3 \%)$ & $0(0 \%)$ & \\
\hline - Polymenorrhea & $1(3.4 \%)$ & $0(0 \%)$ & \\
\hline - Total & $30(100 \%)$ & $29(100 \%)$ & \\
\hline \multicolumn{4}{|l|}{ Group (II) : Electrocautery } \\
\hline - Normal cycle & $0(0 \%)$ & $26(92.85 \%)$ & \multirow{5}{*}{$<0.01$} \\
\hline - Oligomenorrhea & $20(66.7 \%)$ & $2(7.15 \%)$ & \\
\hline - 2ry amenorrhea & $9(30 \%)$ & $0(0 \%)$ & \\
\hline - Polymenorrhea & $1(3.6 \%)$ & $0(0 \%)$ & \\
\hline - Total & $30(100 \%)$ & $28(100 \%)$ & \\
\hline \multicolumn{4}{|l|}{ Group (III) : Harmonic scalpet } \\
\hline - Normal cycle & $0(0 \%)$ & $26(92.85 \%)$ & \multirow{5}{*}{$<0.01$} \\
\hline - Oligomenorrhea & $21(70.0 \%)$ & $2(7.15 \%)$ & \\
\hline - 2ry amenorrhea & $8(26.6 \%)$ & $0(0 \%)$ & \\
\hline - Polymenorrhea & $1(3.4 \%)$ & $0(0 \%)$ & \\
\hline - Total & $30(100 \%)$ & $28(100 \%)$ & \\
\hline
\end{tabular}

Values are given as [No. (\%)].

Post induction menstrual pattern:

Group I and group III; $\mathrm{p}<0.05$.
Group I and group II; $\mathrm{p}<0.05$.

Group II and group III; $\mathrm{p}<0.05$.

Table III : Pre induction and post induction hormonal levels in the three groups .

\begin{tabular}{|c|c|c|c|}
\hline Hormone & Pre induction & Post induction & Pvalue \\
\hline Group (I) : Clomiphene citrate & & & \\
\hline LH (IU/L) & $12.87 \pm 2.28$ & $9.67 \pm 1.6$ & $<0.05$ \\
\hline FSH (IU/L) & $5.9 \pm 1.2$ & $6.0 \pm 1.1$ & $>0.05$ \\
\hline LH/FSH ratio & $2.25 \pm 0.56$ & $1.64 \pm 0.4$ & $<0.05$ \\
\hline Testosterone (ng/mL) & $0.95 \pm 0.15$ & $0.66 \pm 0.129$ & $<0.05$ \\
\hline Estradiol (pg/mL) & $75.3 \pm 4.87$ & $74.8 \pm 5.5$ & $>0.05$ \\
\hline LH (IU/L) & & & \\
\hline FSH (IU/L) & $13.1 \pm 2.1$ & $8.23 \pm 1.1$ & $<0.05$ \\
\hline LH/FSH ratio & $5.69 \pm 0.93$ & $6.0 \pm 1.0$ & $>0.05$ \\
\hline Testosterone (ng/mL) & $2.36 \pm 0.54$ & $1.4 \pm 0.3$ & $<0.05$ \\
\hline Estradiol (II) $:$ Electrocautery $/ \mathrm{mL})$ & $13.1 \pm 2.1$ & $8.23 \pm 1.1$ & $<0.05$ \\
\hline LH (IU/L) & $5.69 \pm 0.93$ & $6.0 \pm 1.0$ & $>0.05$ \\
\hline FSH (IU/L) & & & \\
\hline LH/FSH ratio & $13.1 \pm 2.1$ & $8.23 \pm 1.1$ & $<0.05$ \\
\hline Testosterone (ng/mL) & $5.69 \pm 0.93$ & $6.0 \pm 1.0$ & $>0.05$ \\
\hline Estradiol (pg/mL) & $2.36 \pm 0.54$ & $1.4 \pm 0.3$ & $<0.05$ \\
\hline Group (III) Harmonic scalpet & $13.1 \pm 2.1$ & $8.23 \pm 1.1$ & $<0.05$ \\
\hline & $5.69 \pm 0.93$ & $6.0 \pm 1.0$ & $>0.05$ \\
\hline
\end{tabular}

Values are given as mean $\pm S D$.

Between groups ( $p>0.05$ 
Table IV : Pre and pot induction ultrasonographic characteristics of the three groups.

\begin{tabular}{|c|c|c|c|}
\hline Variable & Pre induction & Post induction & P value \\
\hline Group (I) : Clomiphene citrate & & & \\
\hline Ovarian volume $\left(\mathrm{cm}^{3}\right)$ & $11.68 \pm 2.4$ & $11.2 \pm 1.7$ & $>0.05$ \\
\hline Antral follicle count (AFC) & $16.0 \pm 1.9$ & $15.4 \pm 1.8$ & $>0.05$ \\
\hline Group (II) : Electrocautery & & & \\
\hline Ovarian volume $\left(\mathrm{cm}^{3}\right)$ & $11.66 \pm 2.17$ & $10 \pm 1.9$ & $<0.05$ \\
\hline Antral follicle count (AFC) & $16.1 \pm 2.02$ & $14.14 \pm 1.76$ & $<0.05$ \\
\hline Group (III): Harmonic scalpet & & & \\
\hline Ovarian volume $\left(\mathrm{cm}^{3}\right)$ & $12.5 \pm 1.66$ & $11.3 \pm 1.1$ & $>0.05$ \\
\hline Antral follicle count (AFC) & $16 \pm 2.3$ & $115.46 \pm 1.89$ & $>0.05$ \\
\hline
\end{tabular}

Values are given as Mean \pm SD.

Post induction Ultrasonographic Characteristics of the three groups: $\quad$ Group I and group II; $p<0.05$.

Group I and group III; $p>0.05$.

Group II and group III; $p>0.05$.

Table $\mathrm{V}:$ Post induction ovulation and pregnancy rates among the three groups.

\begin{tabular}{|l|c|c|c|}
\hline \multicolumn{1}{|c|}{ Variable } & $\begin{array}{c}\text { Group(I) } \\
(\mathbf{n}=\mathbf{2 9})\end{array}$ & $\begin{array}{c}\text { Group(II) } \\
(\mathbf{n = 2 8 )}\end{array}$ & $\begin{array}{c}\text { Group(III) } \\
(\mathbf{n = 2 8 )}\end{array}$ \\
\hline Ovulation & $24(82.8 \%)$ & $25(89 \%)$ & $26(92.9 \%)$ \\
Pregnancy & $12(41.4 \%)$ & $14(50 \%)$ & $16(57 \%)$ \\
\hline
\end{tabular}

Values are given as No. (\%).

Group I and group III; $\mathrm{p}<0.05$.

Group I and group II; $p<0.05$.

Group II and group III; $p>0.05$.

Table VI : Incidence and type of post LOD adnexal adhesions

\begin{tabular}{|l|c|c|c|}
\hline \multicolumn{1}{|c|}{ Type of adhesion } & $\begin{array}{c}\text { Electrocautery } \\
(\mathbf{n = 1 3 )}\end{array}$ & $\begin{array}{c}\text { Harmonic Scalpel } \\
(\mathbf{n = 1 1})\end{array}$ & \multirow{2}{*}{ P value } \\
\hline None & $10(76.9 \%)$ & $10(90.0 \%)$ & \multirow{2}{*}{$<0.01$} \\
\hline Minimal & $12(15.4 \%)$ & $1(9.1 \%)$ \\
\cline { 1 - 3 } Mild & $1(7.9 \%)$ & $0(0 \%)$ & \\
\hline Total adhesion & $3(23.1 \%)$ & $1(9.1 \%)$ & \\
\hline
\end{tabular}

Values are given as [No. (\%)].

\section{DISCUSSION}

The main goal of infertile women with PCOS is to create ovulation. Bilatemal ovarian wedge resection (BOWR) was proposed by stein and Leventhal (1935) (1). For a long period it was the only treatment available for this syndrome but that technique was completely abandoned because of high incidence of periadnexal adhesions (100\%) in patients who failed to get pregnant after that procedure ${ }^{(2)}$.

When treatment using anti-estrogens commenced and when the good results obtained with these treatments become well known, the surgical technique was discontinued. Clomiphene citrate was used for a long time as a first Line of treatment; the ovulation rate with this drug is about $80-85 \%$. 
However, $15-20 \%$ of women remain anovulatory despite receiving incremental doses of $\mathrm{CC}$. Furthermore, there was a discrepancy between the ovulation and conception rates which was $40-50 \%^{(3)}$.

Consequently, surgical treatment of PCOS was renewed by adoption of minimally invasive laparoscopic surgery. Various laparoscopic techniques have been described with the use of different energy modalities aiming to improve the success rate and decrease the post opeative adhesions.

In the present study, regular menstruation after ovarian drilling was established in $92.8 \%$ of patients in both electrocautery and harmonic scalpel groups. Comparison of the menstrual pattern before and after surgery showed that, oligomenorthea dropped from $66.7 \%$ and $70 \%$ to $7.2 \%$ for both groups, and $2^{\text {ry }}$ amenorhea dropped from $30 \%$ and $26.6 \%$ to $0 \%$ in electrocautery and harmonic scalpel groups respectively. These results are comparable with that of Takeuchi et al. $(2002)^{(4)}$, where regular menstrual pattern was established in $94 \%$ and $88 \%$ and oligomenorrhea dropped to $6 \%$ and $12 \%$ in electrocautery and harmonic scalpel groups respectively. The present study is also comparable to that of Mural et al. (2005) where regualr menstrual pattern was established in $93.3 \%(10)$.

However, Afaf et al. (2000) reported regular menstrual pattern of $80.4 \%$ and oligomenomba of $19.6 \%$ after electrocautery. This difference may be attributed to different criteria used for diagnosis of PCOS or different study size.

In the present study, regular menstrual pattern in the $\mathrm{CC}$ group that was established after induction was $86.2 \%$ whereas oligomenorrhea was $13.8 \%$ and this result is comparable with that of Kovacs et al. $(2003)^{111)}$.

In the present study, the comparison of post induction menstrual pattern between medial induction of ovulation (group I) and surgical induction of ovulation (groups II and III) was statistically significant and in favor of laparoscopic groups.

In the present study the reduction in the mean levels of serum $L H$, LH/FSH ratio and total testosterone in each of the three groups was found to be statistically significant. On the other hand, comparison of hormonal levels of the three groups after induction was statistically insignificant. These results are in agreement with that of Afaf et al. (2000), Takeuchi et al. (2002); Kovacs et al. (2003); Gleeman et al. (2004); Murat et al. (2005); Mustafa and Tulay (2005) and Mohamed and Maha (2005) $(3,5,11-14)$

In the present study we could not find any significant change in the mean levels of estradiol and FSH after induction in any of the three groups. These results are in agreement with Afaf et al. (2000); Takeuchi et al. (2002) and Mustafa and Tulay (2005) $(3,9,13)$

Contrary to our findings, Murat et al. (2005) reported a significant rise of FSH level after laparoscopic ovarian drilling with electrocautery ${ }^{(10)}$. However, we could not find any significant difference in FSH levels after any method of ovulation induction procedure used in this study.

The present study showed no significant reduction in ovarian volume or antral follicle count in CC group or harmonic scalpel groups. On the other hand, the reduction in ovarian volume and antral follicle count was statistically significant in electrocautery group where ovarian volume decreased from $11.6 \pm 2.17$ to $10 \pm 1.9(\mathrm{p}<0.001)$ and the antral follicle count decreased from $16.1 \pm 2$ to $14.1 \pm 1.7$ $(\mathrm{P}<0.001)$. These findings are comparable to the results obtained by Mohamed and Selim (2005) 14 ) who concluded that diminished ovarian reserve might occur after bilateral ovarian drilling but not after $\mathrm{CC}$ 
induction of ovulation. Mohamed and Selim $(2005)^{(14)}$ attributed this reduction of ovarian reserve to the surrounding thermal damage of ovarian tissue that occurred by electrocautery where single drilling resulted in $0.4 \mathrm{ml}$ destruction of ovarian tissue; so an average of $3.2 \mathrm{ml}$ of ovarian volume were destroyed when 8 drillings in both ovaries were done. In the present study, we didn't find any significant reduction in ovarian volume or antral follicle count after ovarian drilling using harmonic scalpel. This can be attributed to the minimal lateral thermal damage to ovarian tissue $(0.05 \mathrm{ml})$ which is approximately $1 / 8$ th of the damage that results by electrocautery. However, the only available study evaluating the use of harmonic scalpel in LOD, done by Takeuchi et al. $(2002)^{(12)}$ didn't evaluate the ultrasonographic changes after LOD but evaluated hormonal changes, ovulation an pregnancy rates, so further studies are needed to evaluate this issue.

In the present study ovulation rate was $92.9 \%$ and $89 \%$ in harmonic scalpel and electrocautery groups respectively. There was no statistically significant differences between the two groups. This result is .

In the present study the incidence of adhesion formation after LOD was $9.1 \%$ and $23 \%$ in harmonic scalpel and electrocautery groups respectively. There was a statistically significant difference between the two groups in favor of harmonic scalpel. Also the type of adhesion was different in the harmonic scalpel group comparable to that of Takeuchi et al. (2002) $)^{(12)}$ where ovulation rate was $94 \%$ in both groups. On the other hand ovulation rate after CC was $82.8 \%$. There was a statistically significant difference as regard to ovulation rate between medical induction of ovulation group (CC group) and surgical induction of ovulation groups (electrocautery and harmonic scalpel groups). These results are in accordance with that of Kovacs et al. $(2003)^{(11)}$ where ovulation rate was $80 \%$ after CC induction. In the present study the pregnancy rates were $57 \%$ and $50 \%$ for harmonic scalpel and electrocautery groups respectively. The difference between the two groups was statistically insignificant. Other studies reported different ovulation and pregnancy rates after using different laparoscopic techniques and are shown in (Table VII). The difference among these variable studies may be attributed to different laparoscopic techniques, different periods of follow up or the use of medical ovulation induction agents as $\mathrm{CC}$ after electrocautery. Takeuchi et al. $(2002)^{(12)}$ reported pregnancy rates of $53 \%$ and $50 \%$ after harmonic scalpel and electrocautery ovarian drilling respectively which is in accordance with the present study. On the other hand pregnancy rate following medical induction of ovulation by $\mathrm{CC}$ was $40 \%$. The differenc between medical induction of ovulation group and the other two groups was statistically significant. Also, the difference between ovulation rate and pregnancy rate in this group was marked. These differences can be attributed to the antifecundity effect of $\mathrm{CC}$ on cervical mucous and endometrium. The above results are comparable to that of Kovacs et al. (2003) (11) where ovulation rate was $80 \%$ and pregnancy rate was $42 \%$. Adhesions According to the American Fertility Society Classification (1988) was minimal and confined to the ovarian surface. On the other hand, in electrocautery group minimal and mild adhesions were present. Many studies assessed adhesion formation following LOD by electrocautery or laser but very few studies assed the incidence of pelvic adhesions following the use of harmonic scalpel in gynecological surgery, so further studies should be directed to evaluate this issue (Table VIII).

\section{CONCLUSION}

Laparoscopic ovarian drilling using harmonic scalpel is a minimally invasive procedure, leads to monofollicular development which eliminates the need for cycle monitoring and risk of multiple pregnancies or ovarian hyper-stimulation that 
Table VII : Ovulation and pregnancy rates obtained from different laparoscopic treatments of PCOS.

\begin{tabular}{|c|c|c|c|}
\hline Reference & Technique & $\%$ ovulation & \% pregnancies \\
\hline Cohen et al. $(1972 \mathrm{a}, \mathrm{b})^{(15)}$ & Biopsy & 85 & 41 \\
\hline Gjoannaess $(1984)^{(16)}$ & Cauterization & 92 & 84 \\
\hline Greenblatt and Casper $(1987)^{(17)}$ & Cauterization & 71 & 56 \\
\hline Cohen and Audebert (1989) ${ }^{(18)}$ & Cauterization & 80 & 31.8 \\
\hline Huber et al. $(1988)^{(19)}$ & Laser & 41.7 & 23 \\
\hline Daniell and Miller (1989) ${ }^{(20)}$ & Laser & 83.8 & 66.7 \\
\hline Utsunomiyat et al. (1990) $(21)$ & Biopsy & 93.8 & 50 \\
\hline Gadir et al. (1990) & Cauterization & 26.5 & 43.8 \\
\hline Tasaka et al. (1990) & Cauterization & 91 & 36 \\
\hline Gurgan et al. (1991) & Cauterization & 71 & 57 \\
\hline Kovacs etl al. (1991) ${ }^{(25)}$ & Cauterization & 70 & 20 \\
\hline Pellicer and Remohi (1992) ${ }^{(26)}$ & Cauterization & 67 & 52.6 \\
\hline Ostrzenski (1992) 27$)$ & Laser & 92 & 92 \\
\hline Armar and Lachelln $(1993)^{(28)}$ & Cauterization & 86 & 66 \\
\hline Campo et al. (1993) (29) & Resection coelio & 56 & 56 \\
\hline Gjoannaess $(1994)^{(30)}$ & Cauterization & 92 & 84 \\
\hline \multirow[t]{2}{*}{ Takeuchi et al. (2002) } & Harmonic scalpel & 94 & 53 \\
\hline & cauterization & 94 & 50 \\
\hline
\end{tabular}

Takeuchi et al. $(2002)^{\{12\}}$

Table VIII : Periadnexal adhesion formation as assessed by $2^{\text {nd }}$ look laparoscopy following surgical treatment of PCOS.

\begin{tabular}{|c|c|c|}
\hline Reference & Technique & $\%$ of adhesion \\
\hline Portuondo et al. (1984) & Ovarian biopsy & 0 \\
\hline Grochmal (1988) & ND: YAG laser & 3 \\
\hline Lyles ct al. $(1989)^{(33)}$ & Cauterization/ND: YAG laser & 100 \\
\hline Daniell andMiller $(1989)^{(20)}$ & CO2 KTP laser & 0 \\
\hline \multirow[t]{2}{*}{ Keckstein (1989) } & $\mathrm{CO} 2$ laser & 43 \\
\hline & ND: YAG laser & 0 \\
\hline \multirow[t]{2}{*}{ Gurgan et al. (1991) } & Cauterization & 86 \\
\hline & ND: YAG laser & 80 \\
\hline Naether et al. (1994) ${ }^{(35)}$ & Cauterization & 35 \\
\hline Gurgan et al. (1992, (36-37) & ND: YAG laser & 85 \\
\hline Naether \& Fischer (1993) ${ }^{(38)}$ & Cauterization & 19 \\
\hline Dabirashraft et al. (1991) (39) & Cauterization & 0 \\
\hline
\end{tabular}

Naether et al. (1994) (4) 
associates medical induction of ovulation. It has significantly higher ovulation and pregnancy rates, more regular menstrual pattern and with minimal effect on ovarian reserve with minimal incidence of post operative adhesions. So a strategy with diagnostic laparoscopy followed by LOD as a first choice treatment for PCOS is to be performed to shorten the lime to pregnancy for many women. reduce the need for medical ovulation induction and enable diagnosis of those women with anatomic infertility, who can achieve pregnancy only by in vitro fertilizaion.

\section{REFERENCES}

1. Stein IF and Leventhal (1935): Amenorrhea Associated with Bilateral Polycystic ovaries-Am. J Obstet. Gynecol, 29: 181-191.

2. Van der Veen F, Bayrama $N$, van Welya $M$, Bossuytb P. (2005): Laparoscopic electrocautery of the ovaries in patients with clomiphene citrate-resistant polycystic ovary syndrome. International congress Series $1279,24-30$.

3. Afaf Felemban, Seang Lin Tan M, and Togas Tulandi (2002): Laparoscopic treatment of polycystic ovaries with insulated needle cautery: reappraisal fertility and sterility. 73, (2), 266-269.

4. Tracy L. Setji Ann J. Brfown (2007): Polycystic Ovary Syndrome: Diagnosis and Treatment The American Joumal of Medicine 120, 128-132.

5. Cleemann L, FF Lauszus and B. trolle (2004): Laparoscopic ovarian drilling as first line treatment oin infertile women with polycystic ovary syndrome. Gynecol Endocrinol. 18: 138-143.

6. Frank W. Jansen Trudy Trimbos-Kemper and J. Bapits Trimbos (2002): Ultrasonic scalpel in laparoscopic Gynecological surgery; an observational Study in 354 cases. Gynecological endoscopy. 11, 47-51.

7. Sheng Wu, Yi Xue Gong, cheng Xue and Za Zhi (2005): The application and development of uhtrasonic scalpel Chin med. Joumal, 22 (2): 377.
8. Rotterdam FSHRE/ASRM sponsored PCOS Consensus Workshop Group (2004): Revised 2003 consensus on diagnostic criteria and long-term health risks related to polycystic ovary syndrome. Fertil Steril 81(1): 19-25.

9. Takeuchi Shigeto, Noritaka Futamura, Shinichirou Takubo, Naomi Noda, Hiroyuki Minoura and Nagayasu Toyoda (2002): Polycystic Ovary Syndrome Tralled with Laparoscopic Ovarian Drilling with a Harmonic Scalpel: A Prospective. Randomized Study. J Reprod Med; 47: 816: 820.

10. Murat Api, Husnu Gorgen and Ahmet etin (2005): Laparoscopic ovarian drilling in polycystic ovary syndrome. European Journal of Obstetrics \& Gynecology and Reproductive Biology 119, 76-81

11. Kovacs GT, Clarke S, Burger HG, Healy DL, Vollenhoven B. (2003): Polycystic Ovary Syndrome (PCOS)-Surgical or Medical Treatment. A cost benefits analysis. Gynecological Endocrinology; 16 : 53-55.

12. Takeuchi Shigeto, Noritaka Futamura, Shinichirou Takubo, Naomi Noda, Hiroyuki Minoura and Nagyasu Toyoda (2002): Polycystic Ovary Syndrome Treated with Laparoscopic Ovarian Drilling with a Hamonic Scalpel: A Prospective. Randomized Sudy. J Reprod Med; 47: 816: 820.

13. Mustafa Kucu and Tulay Kilic-OkmanMed, (2005): Hormone profiles and clinieal outcome after laparoscopic ovarian drilling in women with polycystic ovary syndrome; 11(1): 29-34.

14. Mohamed Kandil and Maha Selim (2005): Hormonal and Sonographic assessment of ovarian reserve before and after laparoscopic ovarian drilling in polycystic ovary syndrome. B. JOG, 112 , $1427-1430$.

15. Cohen J, Audebert A. De Bux J, and Giorgi $H$. (1972): Biopsics ovarienne d'une grossesse. Nouv. Presse MEd., 1, 1294.

16. Gjoannaess H. (1994): ovarian electrocautery in the treatment of women with PCOS. Acta Obstet. Gynecol. Scand., 73, 407-412.

17. Greenblatt E. and Casper RF. (1987): Endocrine changes aftr Laparoscopic ovarian cautery in polycystic ovarian syndrome. Am. J, Obstet. 
Gynecol., 42, 517-518

18. Cohen J and Audebert AJM (1989): De la mécanique au fonctionnel: place des traitements chirurgicaux in endoscopiques dans lesdystrophies ovariennes. In Dystrophies ovairennes. Masson Éditeur, Paris, ISBN 2 225-81820-7, pp. 183-192.

19. Huber J, Hosmann J, and Spona J. (1988): Polycystic ovarian syndrome treated by laser through the laparoscope. Lancet, 2, 215-200.

20. Daniell JF and Miller N. (1989): Polycystic ovaries treated by laparoscopic laser vaporization. Fertil. Steril., 51, 232-23.

21. Utsunomiya T, Sumioki T, and Taniguchi I. (1990): Hormonal and clinical effecs of maltifollicular puncture and resection of PCOS. Horm. Res. 33, (2), 35.

22. Gadir A, Mowafi R, et al. (1990): Ovarian electrocautery versus HMG and pure FSH therapy in the treatment of PCOD. Clin. Endocrinol, 33. 585-592.

23. Tasaka K, Sakata M, Kurachi H, Komura H, Miayake A, and Tanizawa O. (1990): Electrocautery in PCOS. Horm. Res., 33, 40-42.

24. Gurgan T, Kisnisei H, et al. (1991): Evaluation of adhesions formation after laparoscopic treatment of PCOD. Fertil, Steril., 56, 1176-1178.

25. Kovacs G. Buckler H, et al. (1991): Treatment of anovulation due to PCOS by laparoscopic ovarian cautery. Br. J. Obstet Gynaecol., 98, 30-35.

26. Pellicer A and Remohi J. (1992): Management of the PCOS by Laparoscopy. University of Toronto Medic. Jour 90, (3): 87-89.

27. Ostrzenski A. (1992): Endoscopic carbon dioxide laser wedge fresection in resistant PCO. Int. J. Fertil., 37, 295-299.

28. armar NA and Lachelin G. (1993): Laparoscopic ovarian diathermy: an effective treatment for anti estrogen resistant anovulatory infertility in women with PCOS. Br. J. Obstet. Gynaecol., 100, 161-164.

29. Campo S. Felli A, Lamanna MA et al. (1993): endocrine Changes and clinical outcome after laparoscopic ovarian resection in women with polycystic ovaries. Hum Reprod, 8: $359-363$.

30. Gjoannaess H. (1984): polycystic ovarian syndrome treated by ovarian electrocautery through the laparoscope. Fertil. Steril. 41, 20:25.

31. Portuondo J, Melchor J, Neyro J, and Alegrea A. (1984): Periovarian adhesions following ovarian wedge resections or laparoscopic biopsy. Endoscopy, 16, 143-145.

32. Grochmal S. (1988): Contact ND: YAG laser superior to $\mathrm{CO} 2$ for the treatment of ovarian disease. Laser Practice Rep., 3, 1S.

33. Lyles R, Goldzieher JW, et al. (1989): Early second look lapaloseopy after the treatment of PCO. The 45th Annual Meeing of the American Ferility Society, San Francisco, 13-16 November 1989. Abstr. 0-061 in programmed supplement published by Fertil. Steril, p. 526.

34. Keckstein J. (1989); Laparoscopic treatment of PCOS. Bailliére's Clin. Obstet. Gynecol., 3. 563-581.

35. Naether OG, Baukion V, Fischer R, and Kowalczyk T. (1994): Long-term follow-up in 206 infertility patients with polycystic ovarian syndrome after laparoscopic electrocautery of the ovarian surface. HGum. Reprod., 9, $2342-2349$.

36. Gurgan T, Uman B, et al. (1992); The effect of short internal laparoscopic lysis of adhesions in pregnancy rates following $\mathrm{ND}$ : YAG laser photocoagulation of PCO. Obstet. gynecol., 80, $45-47$.

37. Gurgan T, Uman B, et al. (1992): the effect of short internal laparoscopic lysis of adhesions in pregnancy rates following.

38. Naether $O G$ and Fischer R. (1993): Adhesion formation after laparoscopic electro coagulation of the ovarian surface in polycystic ovary patients. Fertil. Steril, 60, 95-99.

39. Dabirashrafi $\mathrm{H}$, Mohamad $\mathrm{K}$, Behjatnia $\mathrm{Y}$, et al. (1991): Adhesion formation after ovarian electro cauterization on patients with PCO syndrome. Fertil. Steril., 55, 1200-1201. 